\title{
CAT Score and SGRQ Definitions of Chronic Bronchitis as an Alternative to the Classical Definition
}

This article was published in the following Dove Press journal:

International Journal of Chronic Obstructive Pulmonary Disease

Joon Young Choi,' Hyoung Kyu Yoon, $\mathbb{D}^{2}$ Kyeong-Cheol Shin, $\mathbb{D D}^{3}$ So-Young Park, $\mathbb{D}^{4}$ Chang Youl Lee, (iD) ${ }^{5}$ Seung Won Ra, ${ }^{6}$ Ki Suck Jung, ${ }^{7}$ Kwang $\mathrm{Ha} \mathrm{Yoo,} \mathbb{D}^{4}$ ChangHoon Lee, ${ }^{8}$ Chin Kook Rhee $\mathbb{D D}^{9}$

'Division of Pulmonary, Allergy and Critical Care Medicine, Department of Internal

Medicine, St. Vincent's Hospital, The Catholic University of Korea, Suwon, Republic of Korea; ${ }^{2}$ Division of Pulmonary and Critical Care Medicine, Department of Internal Medicine, Yeouido St Mary's Hospital, College of Medicine, The Catholic University of Korea, Seoul, Republic of Korea; ${ }^{3}$ Division of Pulmonology and Allergy, Regional Center for Respiratory Disease, Yeungnam University Medical Center, Daegu, Republic of Korea; ${ }^{4}$ Division of Pulmonary, Allergy and Critical Care Medicine, Department of Internal Medicine, Konkuk University School of Medicine, Seoul, Republic of Korea; ${ }^{5}$ Division of Pulmonary and Critical Care Medicine, Department of Internal Medicine, Chuncheon Sacred Heart Hospital, Hallym University Medical Center, Chuncheon, Republic of Korea; ${ }^{6}$ Division of Pulmonary and Critical Care Medicine, Department of Internal Medicine, Ulsan University Hospital,

University of Ulsan College of Medicine, Ulsan, Republic of Korea; ${ }^{7}$ Division of Pulmonary Medicine, Department of Internal Medicine, Hallym University Sacred Heart Hospital, Hallym University Medical School, Anyang, Republic of Korea; ${ }^{8}$ Division of Pulmonary and Critical Care Medicine, Department of Internal Medicine, Seoul National University College of Medicine, Seoul, Republic of Korea; ${ }^{9}$ Division of Pulmonary, Allergy and Critical Care Medicine, Department of Internal Medicine, Seoul St. Mary's Hospital, College of Medicine, The Catholic University of Korea, Seoul, Republic of Korea

Correspondence: Chin Kook Rhee Division of Pulmonary, Allergy and Critical Care Medicine, Department of Internal Medicine, Seoul St. Mary's Hospital, College of Medicine, The Catholic University of Korea, 222

Banpodaero, Seochogu, Seoul 0659I, Republic of Korea

Tel +82 222586067

Fax +8225993589

Email chinkook77@gmail.com
Purpose: Previous studies have used various definitions to classify chronic obstructive pulmonary disease (COPD) patients into chronic bronchitis (CB) and non-CB patients. This study was performed to identify differences among three definitions of $\mathrm{CB}$ based on the classical method, St. George's Respiratory Questionnaire (SGRQ), and the CAT (COPD Assessment Test) score. Patients and methods: We extracted data from the multicenter Korea COPD Subgroup Study (KOCOSS) cohort, for which patients recruited from among 47 medical centers in South Korea beginning in April 2012. Patients were classified according to three different definitions of CB: 1) classical definition; 2) SGRQ (using questions regarding cough and sputum); and 3) CAT score (comprising cough [CAT1] and sputum [CAT2] subscale scores). Results: A total of 2694 patients were enrolled in this study. The proportions of CB were $10.8 \%, 35.8 \%$, and $24.0 \%$ according to the classical, SGRQ, and CAT definitions, respectively. The three definitions yielded consistently significant differences between CB and nonCB patients in modified Medical Research Council dyspnea scale CAT score, SGRQ score, number of moderate-to-severe exacerbations per year and forced expiratory volume in 1 second. By three definitions, CB consistently predicted future risk of exacerbation. The kappa coefficient of agreement between the classical definition and SGRQ definition was 0.29 , that of the classical definition and CAT definition was 0.32 , and that of the SGRQ definition and CAT definition was 0.44 .

Conclusion: Patients with CB according to the new definitions based on SGRQ or CAT score showed similar clinical characteristics to those defined according to the classical definition. The new $\mathrm{CB}$ definitions may be used as alternatives to the classical definition.

Keywords: chronic bronchitis, CAT score, SGRQ score, chronic obstructive pulmonary disease, KOCOSS database

\section{Introduction}

Chronic obstructive pulmonary disease (COPD) is a major public health problem affecting 328 million patients worldwide; ${ }^{1,2}$ it is also the third leading cause of death worldwide and carries a significant economic burden. Recent studies have indicated the heterogeneity of COPD, and the clinical characteristics of diverse phenotypes have been investigated. ${ }^{3-6}$ Emphysema and chronic bronchitis (CB) have historically been regarded as two important phenotypes. ${ }^{7,8}$ Although many patients show either both or neither of these features, significant numbers of patients show predominantly only one of these phenotypes. 5,7

Patients with CB phenotype are characterized by chronic cough and sputum production. ${ }^{3}$ Goblet cell hyperplasia in the bronchial epithelium is an important pathophysiological mechanism underlying this phenotype, which results in hypersecretion of 
mucus leading to airway obstruction and a predisposition to bacterial colonization. ${ }^{3,9-11}$ Recent reports indicated that $\mathrm{CB}$ phenotype is associated with poor health-related quality of life, ${ }^{3,12-15}$ reduced lung function, ${ }^{12,14}$ more frequent exacerbations, ${ }^{3,7,12,14,16,17}$ and higher mortality rate. ${ }^{14,16}$ These CB patients have been reported to constitute $14-74 \%$ of all COPD patients. ${ }^{17}$ The wide range of prevalence may be due to differences in study design or definitions of $\mathrm{CB}$ between studies.

$\mathrm{CB}$ is usually defined as frequent cough and sputum production for 3 months per year over 2 consecutive years. ${ }^{18-20}$ In addition, various studies have used other definitions to classify $\mathrm{COPD}$ patients into $\mathrm{CB}$ and non- $\mathrm{CB}$ groups. ${ }^{12,21-25}$ Therefore, study heterogeneity has imposed some limitations on interpreting the prevalence and outcome of $\mathrm{CB}$, and there have been several interesting reports regarding differences in clinical outcomes in $\mathrm{CB}$ patients classified according to different definitions. ${ }^{24,25}$ Many studies have used the St. George's Respiratory Questionnaire (SGRQ) score to define CB. ${ }^{26,27}$ The SGRQ consists of 76 questions correlated with health-related quality of life in COPD patients. $^{28}$ Two questions inquire about symptoms of cough and sputum within 1 month, and these may be used as alternatives to investigations based on the classical definition. The COPD Assessment Test (CAT) score consists of cough (CAT1) and sputum (CAT2) scales, and may also be used to classify CB patients. Lim et al recently used SGRQ and CAT scores to categorize COPD patients as $\mathrm{CB}$ or non-CB and confirmed similar clinical and radiological outcomes between $\mathrm{CB}$ patient groups defined according to different definitions. ${ }^{25}$ However, there is a lack of evidence for use of the CAT score to define CB, as clinical outcomes have not been compared with those based on the classical definition used in most studies.

This study was performed to compare clinical characteristics between $\mathrm{CB}$ and non-CB groups categorized according to three different definitions of CB. Moreover, we calculated the sensitivity, specificity, negative predictive value (NPV), and positive predictive value (PPV) for the classical and new definitions of $\mathrm{CB}$, and evaluated the agreement among the three definitions.

\section{Methods}

\section{Study Design, Study Population, and Data Collection}

The Korea COPD Subgroup Study (KOCOSS) cohort is a multicenter COPD cohort study of patients recruited from the pulmonary departments of 54 medical centers in South Korea, beginning in April 2012. The inclusion criteria were South Korean patients more than 40 years old with a ratio of forced expiratory volume in 1 second (FEV1) to forced vital capacity (FVC) ratio $\leq 0.7$ after bronchodilator treatment. In this study, we extracted the data from the KOCOSS cohort, enrolled until 14 June 2018, to evaluate alternative CB definitions based on SGRQ and CAT scores.

\section{Classical, SGRQ, and CAT Definitions of CB}

Three definitions of $\mathrm{CB}$ were evaluated in this study. In accordance with the classical definition, patients who answered "yes" to all of the following questions were classified as having CB: 1) Do you have cough most days, at least 3 months per year? 2) Have you had cough for more than 2 consecutive years? 3) Do you have sputum most days, at least 3 months per year? 4) Have you had sputum production for more than 2 consecutive years? ${ }^{12,13,16,19,29}$

The SGRQ definition of $\mathrm{CB}$ was based on that of previous studies using questions from the SGRQ: 1) How often do you complain of cough during the week? 2) How often do you complain of sputum production during the week? ${ }^{24-27}$ Patients answering "most days of the week" or "several days of the week" to both of these questions were classified as having $\mathrm{CB}$.

As proposed by Lim et al, the CAT definition of $\mathrm{CB}$ was based on the CAT score in patients with both CAT 1 (cough) and 2 (sputum) scores $\geq 3$. $^{25}$

\section{Clinical Parameters}

Clinical patient parameters, including age, sex, smoking history, and body mass index (BMI), were evaluated. We also evaluated parameters relevant to COPD, such as the modified Medical Research Council (mMRC) scale score, CAT total score, SGRQ total score, number of moderate-to -severe exacerbations per year, and number of severe exacerbations per year. Moderate exacerbation was defined as that requiring administration of antibiotics or oral corticosteroids on an outpatient basis. Exacerbation that led to an emergency room visit or hospital admission was defined as severe. ${ }^{30}$ Patients with high risk were defined as more than 2 moderate exacerbations or 1 severe exacerbation per year. Furthermore, pulmonary function test parameters, including FEV1, FVC, FEV1/FVC ratio, diffusion capacity of the lung for carbon monoxide (DLCO), 
and ratio of residual volume to total lung capacity (RV/ TLC) were also analyzed.

\section{Statistical Analysis}

All statistical analyses were performed with $\mathrm{R}$ software (ver. 3.5.2; R Development Core Team, Vienna, Austria). Continuous variables are reported as means \pm standard deviation (SD), and categorical variables are shown as numbers and percentages. We compared the clinical characteristics of $\mathrm{CB}$ and non-CB patients defined according to the three definitions outlined above. Categorical variables were compared between two groups with the $\chi^{2}$ test, and continuous variables were analyzed by Student's $t$ test. In all analyses, $P<0.05$ was taken to indicate statistical significance.

We performed multiple logistic regression for high risk with each $\mathrm{CB}$ definitions, sex, age, smoking history (current smoker vs ex- or never smoker) and FEV1. We used receiver operating characteristics (ROC) curve analysis for each model and calculated area under the curve (AUC) for the most fitting model. We calculated the sensitivity, specificity, PPV, and NPV of the new CB definitions (SGRQ and CAT definitions) compared to the classical definition. In addition, we performed Cohen's kappa test to evaluate agreement among the three different definitions. A $\kappa$ value between 0.01 and 0.20 represents slight, $0.21-0.40$ fair, 0.41-0.60 moderate, 0.61-0.80 substantial, and 0.81-1 almost perfect agreement. $^{31}$

\section{Ethics}

Written informed consent was obtained from all patients enrolled in this study. Ethical approval was obtained from the ethics committees of each participating medical center. The names of the approving ethics committees are listed in Supplementary information.

\section{Results}

\section{Baseline Characteristics}

A total of 2694 COPD patients were enrolled in the KOCOSS cohort from April 2012 to June 2018. The baseline characteristics of the study population are shown in Table 1 . The mean age was $69.2 \pm 8.0$ years and $92.0 \%$ of the patients were male. The mean total CAT score and SGRQ score were $14.7 \pm 8.0$ and $31.9 \pm 18.8$, respectively. The patients suffered moderate-to-severe exacerbation and severe exacerbation $0.5 \pm 1.4$ and $0.1 \pm 0.5$ times per year, respectively. Mean FEV1 was $1.7 \pm 0.6 \mathrm{~L}(62.1 \%$
Table I Baseline Characteristics of COPD Patients $(\mathrm{N}=2694)$

\begin{tabular}{|l|l|}
\hline Characteristics & Overall \\
\hline Mean age (years, mean \pm SD) & $69.2 \pm 8.0$ \\
\hline Sex (n, \%) & \\
Female & $211(8.0 \%)$ \\
Male & $2420(92.0 \%)$ \\
\hline Smoking & \\
Current smoker (n, \%) & $690(26.7 \%)$ \\
Pack-years (mean \pm SD) & $42.4 \pm 25.9$ \\
\hline Body mass index (mean \pm SD) & $23.0 \pm 3.4$ \\
mMRC dyspnea scale score & $1.3 \pm 0.9$ \\
CAT total score (mean \pm SD) & $14.7 \pm 8.0$ \\
SGRQ total (mean \pm SD) & $31.9 \pm 18.8$ \\
Moderate-to-severe exacerbations/y & $0.5 \pm 1.4$ \\
Severe exacerbations/year & $0.1 \pm 0.5$ \\
FEVI (absolute, L) & $1.7 \pm 0.6$ \\
FEVI (\% predicted) & $62.1 \pm 19.2$ \\
FVC (absolute, L) & $3.3 \pm 0.8$ \\
FVC (\% predicted) & $85.4 \pm 17.3$ \\
FEVI/FVC (\%) & $51.3 \pm 12.4$ \\
DLCO, \% predicted & $73.2 \pm 23.1$ \\
RV/TLC (\%) & $43.9 \pm 14.1$ \\
\hline
\end{tabular}

Abbreviations: SD, standard deviation; mMRC, modified Medical Research Council; CAT, COPD Assessment Test; SGRQ, St. George's Respiratory Questionnaire; FEVI, forced expiratory volume in I second; FVC, forced vital capacity; DLCO, diffusion capacity of the lung for carbon monoxide; RV/TLC, ratio of residual volume to total lung capacity.

$\pm 19.2 \%$ ) and mean FEV1/FVC was $51.3 \% \pm 12.4 \%$. The mean predicted DLCO percentage was $73.2 \% \pm 23.1 \%$.

Differences in clinical characteristics between $\mathrm{CB}$ and non-CB patients classified according to the classical definition are shown in Table 2A. Classical CB patients accounted for $10.8 \%$ of COPD patients. There were no significant differences between the two groups in age, sex, smoking history, severe exacerbation history, or RV/TLC. However, CB patients showed lower BMI $(22.5 \pm 3.2$ vs $23.1 \pm 3.4$, respectively) and a higher symptom score on the mMRC dyspnea scale $(1.7 \pm 1.0$ vs $1.3 \pm 0.9$, respectively), higher CAT total score $(21.1 \pm 8.3$ vs $13.9 \pm 7.6$, respectively), and higher SGRQ total score $(45.7 \pm 21.7$ vs $30.3 \pm 17.8$, respectively). In addition, there were significant differences in moderate-to-severe exacerbation risk between $\mathrm{CB}$ and nonCB patients $(0.9 \pm 1.8$ vs $0.5 \pm 1.3$ per year, respectively) and CB patients had a lower FEV1\% predicted $(56.0 \% \pm 18.1 \%$ vs $62.2 \% \pm 19.4 \%$, respectively) and FEV1/FVC ratio $(47.0 \% \pm 12.3 \%$ vs $51.6 \% \pm 12.3 \%$, respectively).

Differences in clinical characteristics between $\mathrm{CB}$ and non-CB patients classified according to the SGRQ 


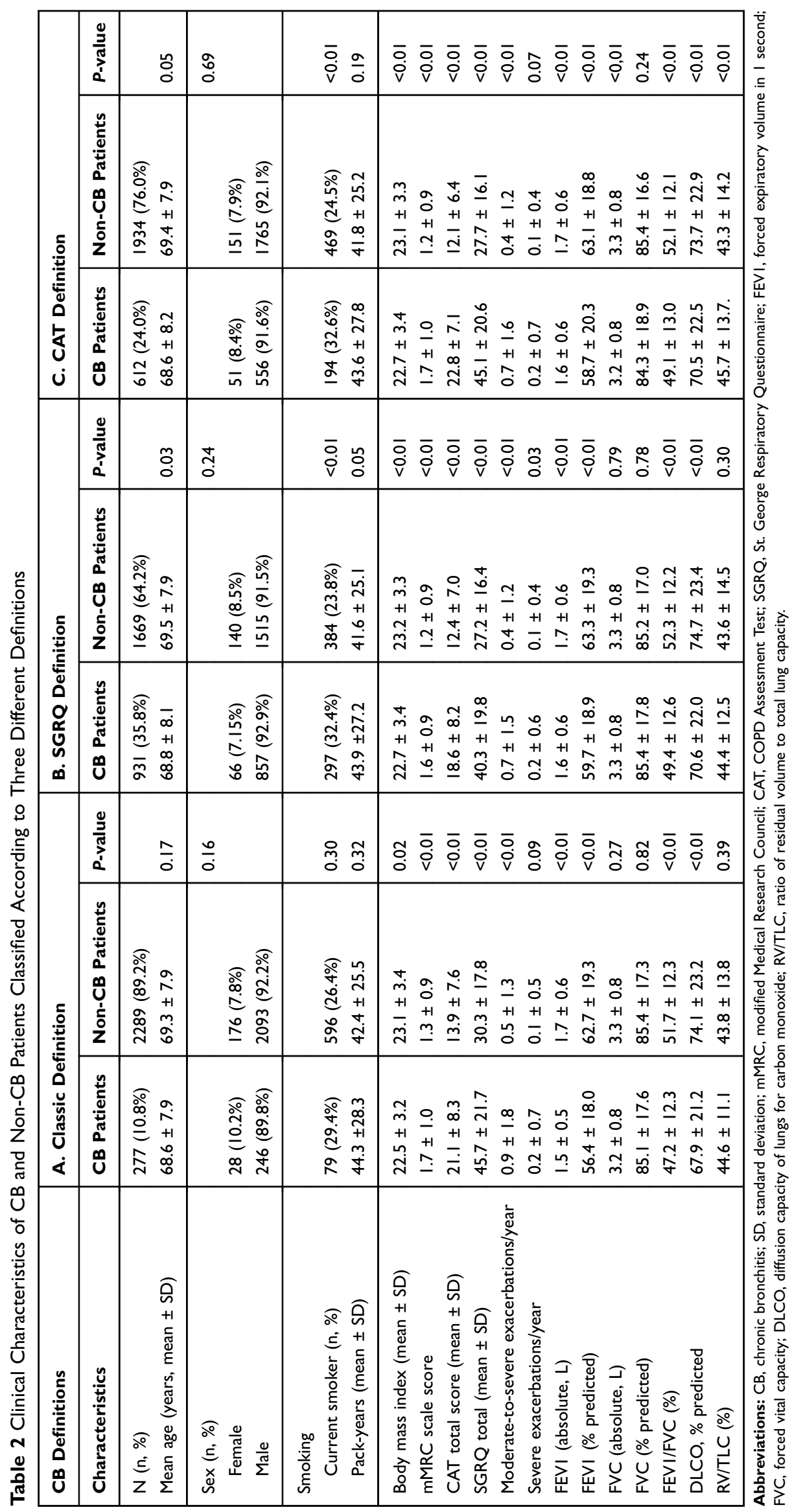


definition are shown in Table 2B. CB patients accounted for $35.8 \%$ of the COPD patients. There were no significant differences between the two groups in age, sex, or RV/TLC. CB patients were more likely to be current smokers (32.4\% vs $23.8 \%$, respectively) and had lower BMI (22.7 \pm 3.4 vs $23.2 \pm 3.3$, respectively). CB patients also showed higher symptom scores on the mMRC (1.6 \pm 0.9 vs $1.2 \pm 0.9$, respectively), higher CAT total score (18.6 \pm 8.2 vs $12.4 \pm 7.0$, respectively), and higher SGRQ total score $(40.3 \pm 19.8$ vs $27.2 \pm 16.4$, respectively) compared to non-CB patients. $\mathrm{CB}$ patients classified according to SGRQ score showed higher risk of both moderate-to-severe exacerbation $(0.7 \pm 1.5$ vs $0.4 \pm 1.2$, respectively) and severe exacerbation $(0.2 \pm 0.6$ vs $0.1 \pm$ 0.4, respectively). Also, $\mathrm{CB}$ patients showed poorer lung function than non-CB patients according to $\mathrm{FEV} 1 \%$ predicted $(59.7 \pm 18.9$ vs $63.3 \% \pm 19.3 \%$, respectively) and FEV1/FVC $(49.4 \pm 12.6$ vs $52.3 \% \pm 12.2 \%$, respectively), consistent with the classical definition. Furthermore, $\mathrm{CB}$ patients classified according to the SGRQ definition showed lower DLCO than the non-CB patients $(70.6 \pm 22.0$ vs $74.7 \pm 23.4$, respectively).

Differences in clinical characteristics between $\mathrm{CB}$ and non-CB patients classified according to the CAT definition are shown in Table 2C. CB patients accounted for $24.0 \%$ of the COPD patients using this definition. There were no differences in age or sex between the two groups. As with the SGRQ score, more CB patients were current smokers (32.6\% vs $24.5 \%$, respectively), but there was no significant difference in pack-years between groups. There was no significant difference in severe exacerbation history, but a significant difference was observed in moderate-to-severe exacerbation between the $\mathrm{CB}$ patients and non-CB patients $(0.7 \pm 1.6$ vs $0.4 \pm 1.2$, respectively). Consistent with the previous two definitions, CB patients showed low BMI (22.7 \pm 3.4 vs $23.1 \pm 3.3$, respectively), higher symptom scores on the mMRC $(1.7 \pm 1.0$ vs $1.2 \pm 0.9$, respectively), higher CAT total score ( $22.8 \pm 7.1$ vs $12.1 \pm 6.4$, respectively), higher SGRQ total score ( $45.1 \pm 20.6$ vs $27.7 \pm 16.1$, respectively), and lower FEV1\% predicted $(58.7 \% \pm 20.3 \%$ vs $63.1 \% \pm$ $18.8 \%$, respectively), FEV1/FVC ( $49.1 \% \pm 13.0 \%$ vs $52.1 \%$ $\pm 12.1 \%$, respectively), and DLCO $(70.5 \pm 22.5$ vs $73.7 \pm$ 22.9, respectively). RV/TLC was significantly different between the $\mathrm{CB}$ and non-CB groups $(45.7 \pm 13.7$ vs $43.3 \pm$ 14.2 , respectively), whereas it was not significantly different using the previous two definitions.

\section{Association of CB Phenotype by Each definition and Risk of Exacerbation}

The result of multiple logistic regression to reveal an association between $\mathrm{CB}$ phenotype by each definition and risk of exacerbation is shown in Table 3. By three different models, the results consistently showed that $\mathrm{CB}$ phenotype, age and FEV1 were associated with high risk of exacerbation. The odds ratio for high risk with three $\mathrm{CB}$ definitions (classic, SGRQ, CAT) were 2.39, 1.83 and 1.69 , respectively. ROC curve analysis was shown in Figure 1. Area under the curve (AUC) was calculated as $0.70,0.71$ and 0.70 , respectively.

\section{Discrepancies in Patient Groups Among the Three Different Definitions of CB}

The discrepancies in patient groups among the three different definitions of $\mathrm{CB}$ are shown in Figure 2. Among the patients classified as $\mathrm{CB}$ by the classical definition, $87.3 \%$ and $68.5 \%$ were reclassified as $\mathrm{CB}$ according to the SGRQ and CAT definitions, respectively. In addition, among $\mathrm{CB}$ patients defined according to the SGRQ definition, $26.4 \%$ and $50.4 \%$ were classified as $\mathrm{CB}$ according to the classical and CAT definitions, respectively. Finally, in patients classified as CB according to the CAT definition, $30.3 \%$ and $75.0 \%$ were classified as CB according to the classical and SGRQ definitions, respectively.

Table 3 Multiple Logistic Regression of CB Phenotype of Each Definition with High-Risk Group

\begin{tabular}{|l|l|l|l|l|l|l|l|l|}
\hline Variable & OR $(\mathbf{9 5} \% \mathbf{~ C I})$ & $\boldsymbol{P}$-value & Variable & OR $(\mathbf{9 5} \% \mathbf{C I})$ & $\boldsymbol{P}$-value & Variable & OR (95\% CI) & $\mathbf{p}$-value \\
\hline CB (Classic) & $2.39(1.53-3.73)$ & $<0.01$ & CB (SGRQ) & $1.83(1.30-2.57)$ & $<0.01$ & CB (CAT) & $1.69(1.17-2.44)$ & $<0.01$ \\
Sex (male) & $1.39(0.76-2.57)$ & 0.29 & Sex (male) & $1.54(0.85-2.78)$ & 0.16 & Sex (male) & $1.58(0.87-2.86)$ & 0.14 \\
Age & $1.04(1.02-1.07)$ & $<0.01$ & Age & $1.04(1.02-1.07)$ & $<0.01$ & Age & $1.05(1.02-1.07)$ & $<0.01$ \\
Current smoker & $0.81(0.52-1.26)$ & 0.35 & Current smoker & $0.75(0.48-1.07)$ & 0.21 & Current smoker & $0.84(0.54-1.31)$ & 0.43 \\
FEVI & $0.97(0.96-0.98)$ & $<0.01$ & FEVI & $0.97(0.96-0.98)$ & $<0.01$ & FEVI & $0.97(0.96-0.98)$ & $<0.01$ \\
\hline
\end{tabular}

Note: Hosmer and Lemeshow goodness-of-fit test: $P$-value was $0.37,0.44,0.61$, respectively.

Abbreviations: OR, odd ratio; $\mathrm{Cl}$, confidence interval; $\mathrm{CB}$, chronic bronchitis; CAT, COPD Assessment Test; SGRQ, St. George Respiratory Questionnaire; FEVI, forced expiratory volume in I second. 


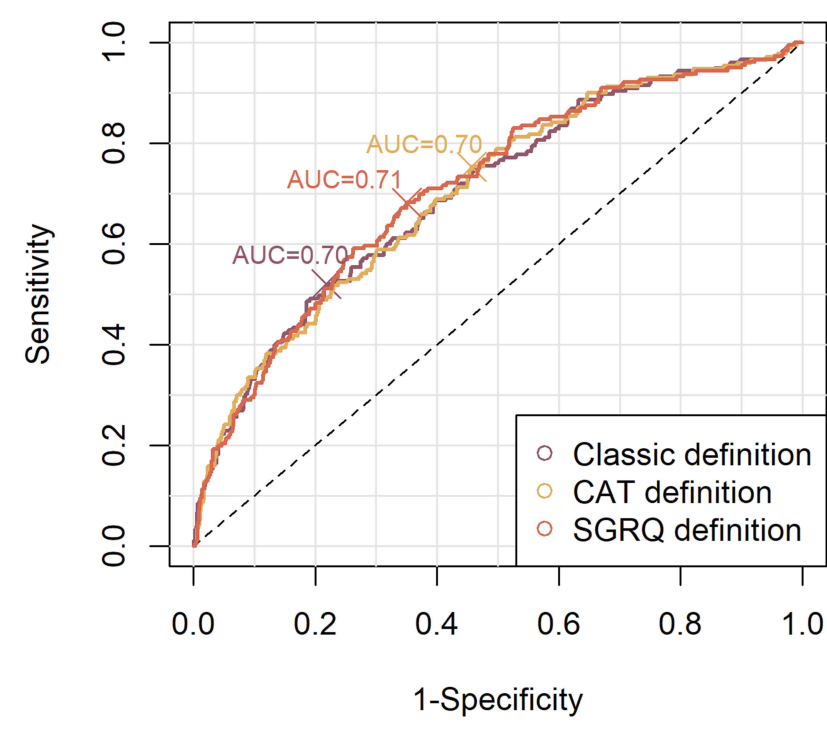

Figure I ROC curve analysis for three different logistic regression models predicting future exacerbation risk by three definitions of $\mathrm{CB}$.

Abbreviations: ROC, Receiver operating characteristic; $C B$, chronic bronchitis.

We calculated the sensitivity, specificity, PPV, and NPV of the two new CB definitions (ie, SGRQ and CAT definitions) compared to the classical definition (Table 4). Classification of CB patients with the SGRQ definition showed sensitivity and specificity of $87.2 \%$ and $70.5 \%$, respectively. In addition, the PPV and NPV were $26.4 \%$ and $97.9 \%$, respectively, in comparison with the classical definition. Moreover, classification using the CAT definition showed sensitivity and specificity of $68.5 \%$ and $81.1 \%$, respectively, compared with the classical definition. PPV and NPV were $30.3 \%$ and $95.6 \%$, respectively.
Table 4 Sensitivity, Specificity, PPV, and NPV of the New CB Definitions Compared to the Classical Definition

\begin{tabular}{|l|l|l|}
\hline & SGRQ Definition & CAT Definition \\
\hline Sensitivity & 87.2 & 68.5 \\
Specificity & 70.5 & 81.1 \\
PPV & 26.4 & 30.3 \\
NPV & 97.9 & 95.6 \\
\hline
\end{tabular}

Abbreviations: SGRQ, St. George Respiratory Questionnaire; CAT, COPD Assessment Test; PPV, positive predictive value; NPV, negative predictive value.

\section{Results of Kappa Coefficient Test}

The results of Cohen's kappa test of agreement between the three $\mathrm{CB}$ definitions are shown in Figure 3. The $\kappa$ value for the classical definition and the SGRQ definition was 0.29 , and that for the classical definition and the CAT definition was 0.32 ; thus, there was fair agreement in both cases. Moreover, the $\kappa$ value for the SGRQ and CAT definitions was 0.44 , indicating moderate agreement.

\section{Discussion}

The present study was performed to investigate two alternative definitions of $\mathrm{CB}$, using SGRQ and CAT subscale scores pertaining to cough and sputum production, which could replace the classical definition. We compared the clinical parameters of $\mathrm{CB}$ and non-CB patients classified according to each definition, and the results showed that CB patients classified according to both alternative definitions showed similar results regarding clinical manifestations compared to those classified according to the classical definition. According to both of the new
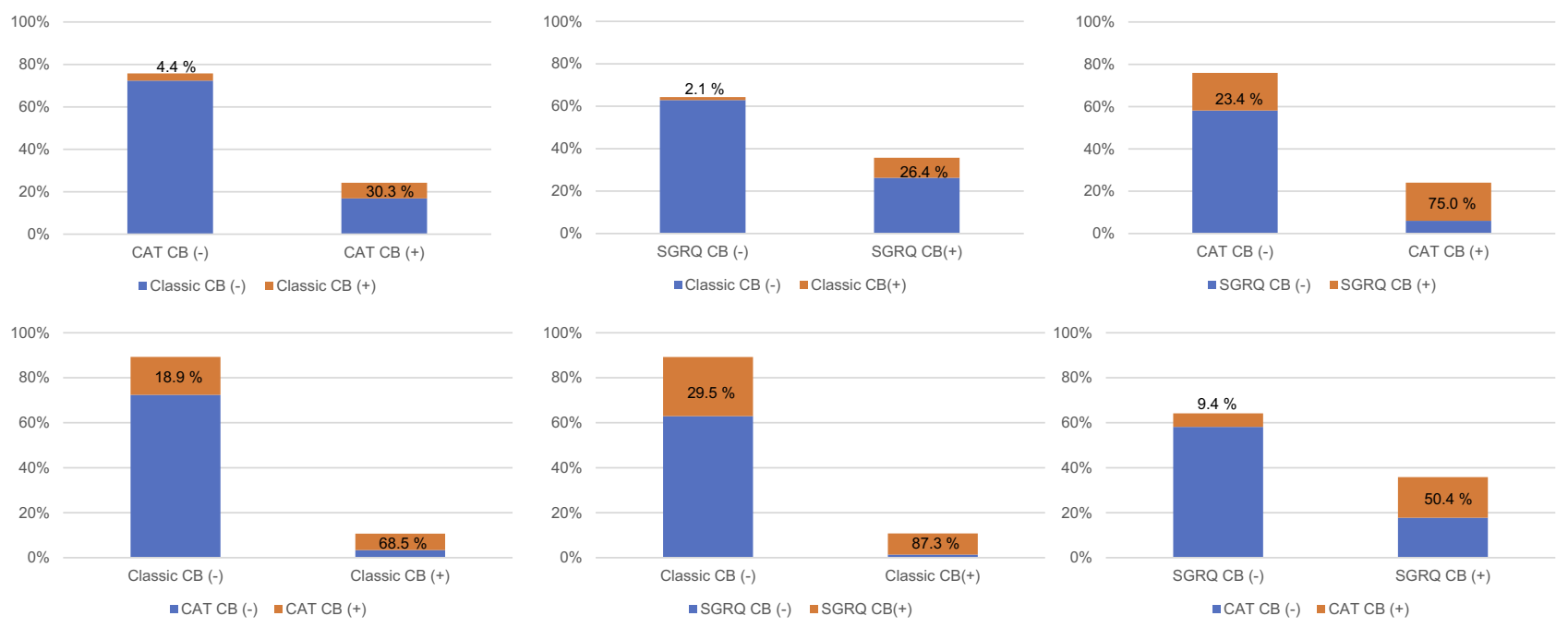

Figure 2 Discrepancies in patient groups among the three different definitions of $C B$.

Abbreviations: CB, chronic bronchitis; SGRQ, St. George's Respiratory Questionnaire; CAT, COPD Assessment Test. 


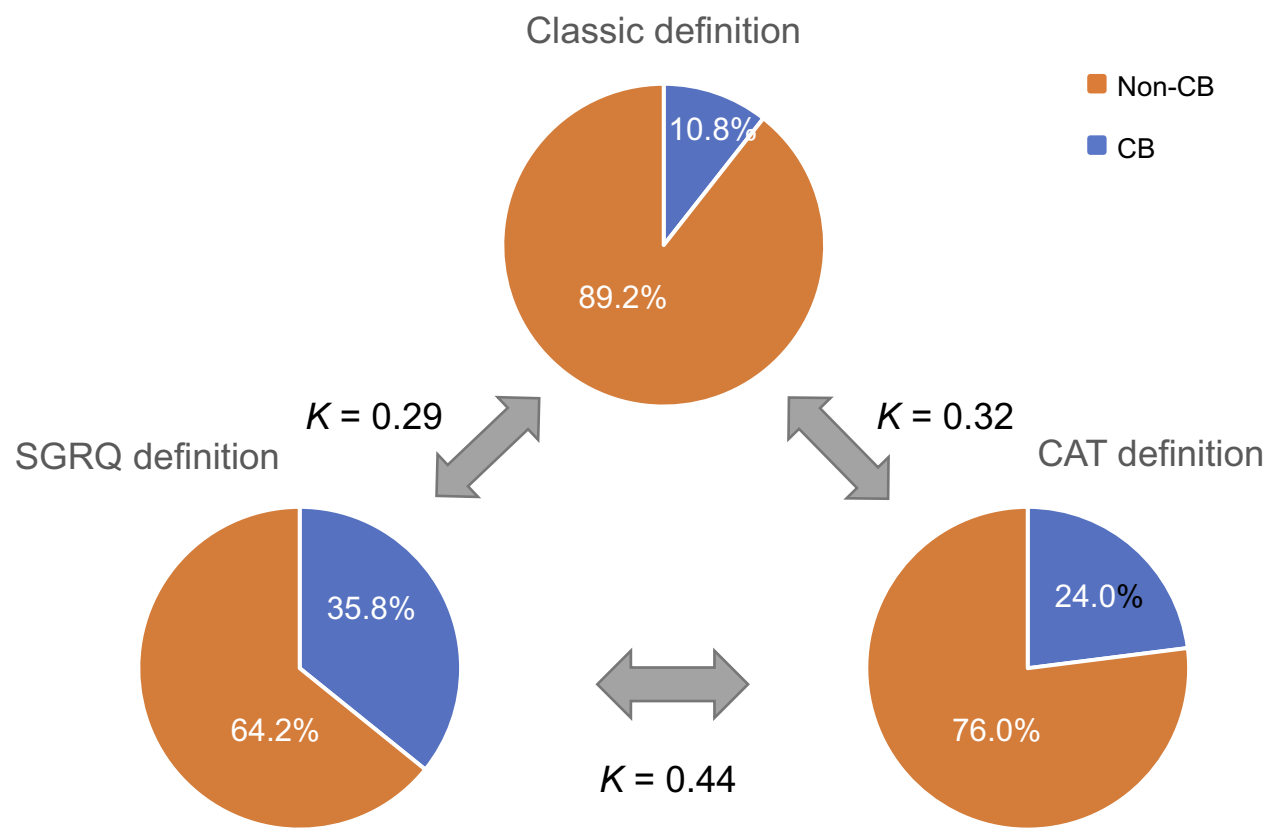

Figure 3 Proportion of $C B$ patients and Cohen's kappa test result for agreement among the three CB definitions.

Abbreviations: CB, chronic bronchitis; SGRQ, St. George's Respiratory Questionnaire; CAT, COPD Assessment Test.

classifications, CB patients were more dyspneic, had more respiratory symptoms, suffered moderate-to-severe exacerbations more frequently, and had lower FEV1 and DLCO. Severe exacerbation tended to be more frequent in $\mathrm{CB}$ patients classified acceding to all three definitions, but statistical significance was found only with the SGRQ definition. By logistic regression analysis, our study proved that $\mathrm{CB}$, defined by all three definitions, was an independent factor for high-risk COPD patients, and these three regression models showed similar performance in predicting high-risk COPD patients. These clinical characteristics of $\mathrm{CB}$ corresponded to those of patients with $\mathrm{CB}$ in previous studies. ${ }^{12-15,29,32}$ Furthermore, the RV/ TLC was significantly higher in the $\mathrm{CB}$ group $\mathrm{CB}$ than the non-CB group classified according to the CAT definition $(P<0.05)$. Although the same tendency was observed with the other definitions, it was not statistically significant in either case.

To determine the clinical importance of respiratory symptoms in COPD patients, many attempts have been made using various methods to classify patients into phenotypes based on such symptoms. In the 1960s, the Medical Research Council (MRC) committee developed the MRC questionnaire and performed an epidemiological investigation of chronic respiratory symptoms. ${ }^{33}$ They defined CB as persistence of cough and production of sputum on most days for 3 months each year, and this definition was widely used. ${ }^{34}$ However, different groups continued to use various methods to define $\mathrm{CB}$, which made it difficult to compare the results between studies. ${ }^{35-37}$ Therefore, the American Thoracic Society (ATS) issued standardized questionnaires in 1978 to define $\mathrm{CB}$, which was identical to the "classical definition" of $\mathrm{CB}$ used in our study. ${ }^{20,24}$

However, there may have been some recall bias using this definition, especially in elderly patients, because of the long-term evaluation period of 2 years. ${ }^{12,25}$ In addition, the term "3 months per year, for 2 consecutive years" may be confusing for both patients and doctors. Furthermore, this definition may be difficult to apply in analyses of retrospective cohort studies. Therefore, there have been a number of attempts to establish other definitions as alternatives to the classical definition, including using the SGRQ score. ${ }^{26,27,38}$

Kim et al compared an alternative definition of $\mathrm{CB}$ based on the SGRQ score with the classical definition and reported that $\mathrm{CB}$ patients classified according to both the classical and SGRQ definitions showed similar clinical and radiological characteristics. ${ }^{24}$ This previous study showed good sensitivity, specificity, and NPV (87\%, 77\%, and 95\%, respectively), similar to our study. In addition, the kappa test showed moderate agreement $(\kappa=0.55)$, where this agreement was stronger than in our study. These results suggested that the SGRQ definition of $\mathrm{CB}$ is a good 
alternative to the classical definition. However, the PPV was significantly low (57\%), as also observed in the present study. This may have been due to the SGRQ definition requiring patients to recall only 4 weeks of respiratory symptoms, in contrast to 2 consecutive years in the classical definition. Therefore, patients with only recent symptoms may have been classified as having CB according to the SGRQ definition, but not the classical definition.

Recently, Lim et al suggested that CAT subscale scores should be used to define $\mathrm{CB} .{ }^{25}$ They investigated the prevalence of $\mathrm{CB}$ in their cohort to inform an adequate cut-off value to define the condition, and developed the CAT definition that was also used in our study. Consistent with our observations, they reported similar clinical and radiological outcomes between $\mathrm{CB}$ groups classified according to the SGRQ and CAT definitions. In the present study, we demonstrated good sensitivity, specificity, and NPV, with fair agreement between the classical and CAT definitions of CB based on the kappa coefficient. However, the PPV was somewhat low, which may have been due to the relatively short period of recall associated with the CAT questionnaires, similar to the SGRQ definition.

The prevalence of $\mathrm{CB}$ differed widely according to the definitions used in our study. The CB prevalence of $24 \%$ according to the CAT definition corresponded to previous population-based studies (14-30\%) and was similar to the target value used when developing the definition (20.4\%). ${ }^{17,25}$ However, the prevalence of CB according to the classical definition was $10.8 \%$ in the present study, which was lower than in previous studies. This may have been due to confusion with the phrase " 2 consecutive years" used in the questionnaire, especially when translated into Korean. ${ }^{12}$ In addition, some studies may have classified more patients as having $\mathrm{CB}$ when they defined $\mathrm{CB}$ based on sputum alone, or used a shorter evaluation period. The CB prevalence according to the SGRQ definition was highest in our study, consistent with two previous studies. $^{24,25}$ This may also have been due to the short evaluation period, such that patients with acute symptoms may have been diagnosed as CB.

This study had some limitations. First, due to its crosssectional design, further longitudinal studies are needed to validate the new $\mathrm{CB}$ definitions. Second, the CAT definition of CB has only been evaluated in the South Korean population. ${ }^{25}$ As our study showed that $\mathrm{CB}$ patients classified using the classical definition constituted a lower proportion of COPD compared to previous studies, the cutoff value of CAT $1 / 2$ used in the CAT definition may need to be readjusted for use in other populations worldwide.

Despite these limitations, this study had a number of strengths. First, we demonstrated the validity of the CAT score for defining $\mathrm{CB}$. As the SGRQ requires considerable time for completion, it is difficult to use routinely in clinical practice. Therefore, the SGRQ has generally been used for research purposes. However, the CAT score can be administered more rapidly than the SGRQ, making it suitable for routine use in clinical practice. Therefore, defining CB according to the CAT score, as in our study, may allow clinicians to identify $\mathrm{CB}$ patients more easily and thus improve the quality of medical services. Second, the analyses in our study were performed in a large number of patients from the KOCOSS cohort database over a period of 6 years.

In this study, $\mathrm{CB}$ patients classified according to new definitions of CB based on SGRQ and CAT scores showed similar clinical characteristics to those classified according to the classical definition. The favorable sensitivity, specificity, and NPV, and fair kappa agreement score suggested that the new $\mathrm{CB}$ definitions may be used as alternatives to the classical definition.

\section{Data Sharing Statement}

Our data is not freely available, and review/approval by IRB is required to be used.

\section{Acknowledgment}

This research was supported by a fund (2016ER670100, 2016ER670101, 2016ER670102 \& 2018ER670100, 201 8ER670101) by Research of Korea Centers for Disease Control and Prevention.

\section{Disclosure}

The authors have no conflicts of interest.

\section{References}

1. Lopez-Campos JL, Tan W, Soriano JB. Global burden of COPD. Respirology. 2016;21(1):14-23. doi:10.1111/resp.12660

2. Kim C, Kim Y, Yang DW, et al. Direct and indirect costs of chronic obstructive pulmonary disease in Korea. Tuberc Respir Dis (Seoul). 2019;82(1):27-34. doi:10.4046/trd.2018.0035

3. Kim V, Han MK, Vance GB, et al. The chronic bronchitic phenotype of COPD: an analysis of the COPDGene Study. Chest. 2011;140 (3):626-633. doi:10.1378/chest.10-2948

4. Mirza S, Benzo R. Chronic obstructive pulmonary disease phenotypes: implications for care. Mayo Clin Proc. 2017;92(7):1104-1112. doi:10. 1016/j.mayocp.2017.03.020

5. Friedlander AL, Lynch D, Dyar LA, Bowler RP. Phenotypes of chronic obstructive pulmonary disease. COPD. 2007;4(4):355-384. doi:10.10 $80 / 15412550701629663$ 
6. Miravitlles M, Soler-Cataluna JJ, Calle M, Soriano JB. Treatment of COPD by clinical phenotypes: putting old evidence into clinical practice. Eur Respir J. 2013;41(6):1252-1256. doi:10.1183/090319 36.00118912

7. Kania A, Krenke R, Kuziemski K, et al. Distribution and characteristics of COPD phenotypes - results from the polish sub-cohort of the POPE study. Int J Chron Obstruct Pulmon Dis. 2018;13:1613-1621. doi:10.2147/COPD.S154716

8. Hogg JC, Chu F, Utokaparch S, et al. The nature of small-airway obstruction in chronic obstructive pulmonary disease. $N$ Engl J Med. 2004;350(26):2645-2653. doi:10.1056/NEJMoa032158

9. Saetta M, Turato G, Baraldo S, et al. Goblet cell hyperplasia and epithelial inflammation in peripheral airways of smokers with both symptoms of chronic bronchitis and chronic airflow limitation. $\mathrm{Am}$ J Respir Crit Care Med. 2000;161(3 Pt 1):1016-1021. doi:10.1164/ ajrccm.161.3.9907080

10. Kim V, Kelemen SE, Abuel-Haija M, et al. Small airway mucous metaplasia and inflammation in chronic obstructive pulmonary disease. COPD. 2008;5(6):329-338. doi:10.1080/1541255080252 2445

11. Kim V, Rogers TJ, Criner GJ. New concepts in the pathobiology of chronic obstructive pulmonary disease. Proc Am Thorac Soc. 2008;5 (4):478-485. doi:10.1513/pats.200802-014ET

12. Choi JY, Yoon HK, Park SJ, et al. Chronic bronchitis is an independently associated factor for more symptom and high-risk groups. Int J Chron Obstruct Pulmon Dis. 2016;11:1335-1341. doi:10.2147/ COPD.S105516

13. Meek PM, Petersen H, Washko GR, et al. Chronic bronchitis is associated with worse symptoms and quality of life than chronic airflow obstruction. Chest. 2015;148(2):408-416. doi:10.1378/chest. 14-2240

14. Kim V, Criner GJ. The chronic bronchitis phenotype in chronic obstructive pulmonary disease: features and implications. Curr Opin Pulm Med. 2015;21(2):133-141. doi:10.1097/MCP.0000000000000 145

15. Yoo SH, Lee JH, Yoo KH, Jung KS, Rhee CK. Different pattern of chronic obstructive pulmonary disease assessment test score between chronic bronchitis and non-chronic bronchitis patients. Tuberc Respir Dis (Seoul). 2018;81(3):228-232. doi:10.4046/trd.2017.0088

16. Lahousse L, Seys LJM, Joos GF, Franco OH, Stricker BH, Brusselle GG. Epidemiology and impact of chronic bronchitis in chronic obstructive pulmonary disease. Eur Respir J. 2017;50(2). doi:10.1183/13993003.02470-2016

17. Corhay JL, Vincken W, Schlesser M, Bossuyt P, Imschoot J. Chronic bronchitis in COPD patients is associated with increased risk of exacerbations: a cross-sectional multicentre study. Int J Clin Pract. 2013;67(12):1294-1301. doi:10.1111/ijcp.12248

18. Ferre A, Fuhrman C, Zureik M, et al. Chronic bronchitis in the general population: influence of age, gender and socio-economic conditions. Respir Med. 2012;106(3):467-471. doi:10.1016/j.rmed.20 11.12 .002

19. de Oca MM, Halbert RJ, Lopez MV, et al. The chronic bronchitis phenotype in subjects with and without COPD: the PLATINO study. Eur Respir J. 2012;40(1):28-36. doi:10.1183/09031936.00141611

20. Ferris BG. Epidemiology standardization project (American thoracic society). Am Rev Respir Dis. 1978;118(6 Pt 2):1-120.

21. Hurst JR, Vestbo J, Anzueto A, et al. Susceptibility to exacerbation in chronic obstructive pulmonary disease. N Engl J Med. 2010;363 (12):1128-1138. doi:10.1056/NEJMoa0909883
22. Pallasaho P, Lundback B, Laspa SL, et al. Increasing prevalence of asthma but not of chronic bronchitis in Finland? Report from the FinEsS-Helsinki study. Respir Med. 1999;93(11):798-809. doi:10.10 16/S0954-6111(99)90265-2

23. Vestbo J, Prescott E, Lange P. Association of chronic mucus hypersecretion with FEV1 decline and chronic obstructive pulmonary disease morbidity. Copenhagen City heart study group. Am J Respir Crit Care Med. 1996;153(5):1530-1535. doi:10.1164/ajrccm.153.5.8630 597

24. Kim V, Crapo J, Zhao H, et al. Comparison between an alternative and the classic definition of chronic bronchitis in COPDGene. Ann Am Thorac Soc. 2015;12(3):332-339. doi:10.1513/AnnalsATS.2014 11-518OC

25. Lim JU, Lee JH, Kim TH, et al. Alternative definitions of chronic bronchitis and their correlation with $\mathrm{CT}$ parameters. Int J Chron Obstruct Pulmon Dis. 2018;13:1893-1899. doi:10.2147/COPD.S16 4055

26. Han MK, Kim V, Martinez CH, et al. Significance of chronic bronchitis in the COPD CRN Azithromycin in COPD Study [abstract]. Am J Respir Crit Care Med. 2012;185:A3736.

27. Kim V, Sternberg AL, Washko G, et al. Severe chronic bronchitis in advanced emphysema increases mortality and hospitalizations. COPD. 2013;10(6):667-678. doi:10.3109/15412555.2013.827166

28. Jones PW, Quirk FH, Baveystock CM, Littlejohns P. A self-complete measure of health status for chronic airflow limitation. The St. George's respiratory questionnaire. Am Rev Respir Dis. 1992;145(6):1321-1327. doi:10.1164/ajrccm/145.6.1321

29. Mejza F, Gnatiuc L, Buist AS, et al. Prevalence and burden of chronic bronchitis symptoms: results from the BOLD study. Eur Respir J. 2017;50(5):1700621. doi:10.1183/13993003.00621-2017

30. Mullerova H, Shukla A, Hawkins A, Quint J. Risk factors for acute exacerbations of COPD in a primary care population: a retrospective observational cohort study. BMJ Open. 2014;4(12):e006171. doi:10. 1136/bmjopen-2014-006171

31. Landis JR, Koch GG. The measurement of observer agreement for categorical data. Biometrics. 1977;33(1):159-174. doi:10.2307/ 2529310

32. Kim V, Criner GJ. Chronic bronchitis and chronic obstructive pulmonary disease. Am J Respir Crit Care Med. 2013;187(3):228-237. doi:10.1164/rccm.201210-1843CI

33. Samet JM. A historical and epidemiologic perspective on respiratory symptoms questionnaires. Am J Epidemiol. 1978;108(6):435-446. doi:10.1093/oxfordjournals.aje.a112642

34. McNab GR, Slator EJ, Stewart CJ. Response to a questionnaire on chronic bronchitic symptoms in East Anglia. Br J Prev Soc Med. 1966;20(4):181-188. doi:10.1136/jech.20.4.181

35. Chronic bronchitis in Great Britain: national survey carried out by the respiratory diseases study group of the college of general practitioners. $\mathrm{Br}$ Med J. 1961;2(5258):973-979. doi:10.1136/bmj.2. 5258.973

36. Gillam PM, Heaf PJ, Hoffbrand BI, Hilton G. Chronic bronchitis and radiotherapy of the lung. Lancet. 1964;1(7345):1245-1248. doi:10. 1016/S0140-6736(64)91870-7

37. Thurlbeck WM, Angus GE. A distribution curve for chronic bronchitis. Thorax. 1964;19:436-442. doi:10.1136/thx.19.5.436

38. Albert RK, Connett J, Bailey WC, et al. Azithromycin for prevention of exacerbations of COPD. N Engl J Med. 2011;365(8):689-698. doi:10.1056/NEJMoa1104623 


\section{Publish your work in this journal}

The International Journal of COPD is an international, peer-reviewed journal of therapeutics and pharmacology focusing on concise rapid reporting of clinical studies and reviews in COPD. Special focus is given to the pathophysiological processes underlying the disease, intervention programs, patient focused education, and self management

protocols. This journal is indexed on PubMed Central, MedLine and CAS. The manuscript management system is completely online and includes a very quick and fair peer-review system, which is all easy to use. Visit http://www.dovepress.com/testimonials.php to read real quotes from published authors.

Submit your manuscript here: https://www.dovepress.com/international-journal-of-chronic-obstructive-pulmonary-disease-journal 